\title{
AVALIAÇÃO TÉCNICA DE UM SISTEMA DE PESAGEM NO CARREGAMENTO FLORESTAL ${ }^{1}$
}

\author{
Eduardo da Silva Lopes² ${ }^{2}$ João Francisco da Costa Cristo ${ }^{3}$ e Mário Pieper ${ }^{4}$
}

\begin{abstract}
RESUMO - Esta pesquisa teve por objetivo avaliar tecnicamente um sistema de pesagem no carregamento de madeira. Os dados foram obtidos em 124 veículos de transporte, em áreas de colheita de madeira de Pinus taeda. A análise técnica englobou um estudo de tempos e movimentos e de produtividade do carregador florestal e determinação da eficiência do sistema de pesagem. Os resultados indicaram que houve aumento no tempo de carregamento devido à necessidade de pausas para estabilização do equipamento. Foi ainda verificado que a diferença média de pesos entre o sistema de pesagem e a balança da fábrica foi de $218 \mathrm{~kg}$, correspondendo a um erro médio de $0,72 \%$. Pelo teste "t", verificou-se que as leituras de pesos obtidos entre o sistema de pesagem e a balança da fábrica não diferiram entre si, comprovando a eficiência do equipamento.
\end{abstract}

Palavras-chave: Transporte florestal, carregador, sistema de pesagem e produtividade.

\section{TECHNICAL EVALUATION OF A WEIGHING SYSTEM IN LOG LOADER}

\begin{abstract}
The objective of this research was to evaluate a weighing system in log loader. Data was obtained from 124 trucks in areas of Pinus taeda harvesting. The operational analysis included a log loader productivity, time and motion study and weighing efficiency evaluation. The analysis revealed that the mean difference between the weighing system and industry weighing was approximately $218 \mathrm{~kg}$, corresponding to a $0.72 \%$ mean error. T-test showed no difference between the weight reading by the weighing system and the industry weighing, proving the equipment efficiency.
\end{abstract}

Keywords: Forest transport, loader, weighing system and productivity.

\section{INTRODUÇÃO}

O transporte de madeira no Brasil é realizado principalmente pelo modo rodoviário, devido à extensa malha viária existente, oferta de diferentes tipos de veículos, seu menor preço inicial e possibilidade de escolha de rotas (MACHADO et al., 2000). Segundo Seixas (2001), trata-se de um setor que em sofrendo pressão de aumento dos custos, em virtude da instalação de postos de pedágios nas rodovias, fiscalização mais rigorosa com relação à "Lei da Balança" e reajustes constantes nos preços dos combustíveis, representando, em média, de 38 a $66 \%$ do custo final da madeira posta-fábrica, em distâncias entre 45 e $240 \mathrm{~km}$, respectivamente.

A "Lei da Balança" é parte do Código Nacional de Trânsito, tendo sido elaborado na década de 1960 e colocado em prática a partir de 1974 , sendo um conjunto de artigos do referido código que dispõe sobre os limites de dimensões e pesos para veículos de carga e de passageiros.

\footnotetext{
${ }^{1}$ Recebido em 21.12.2004 e aceito para publicação em 05.04.2006.

${ }^{2}$ Departamento de Engenharia Florestal da UNICENTRO, 84500-000 Irati-PR. E-mail: <eslopes@irati.unicentro.br>.

${ }^{3}$ Rodo Mar Veículos e Máquinas Ltda, 81690-300 Curitiba-PR. E-mail: <joao.cristo@ rodomar.com.br>.

${ }^{4}$ Paraná Equipamentos S.A., 81690-200 Curitiba-PR. E-mail: <mario_pieper/pesa@ pesa.com.br>.
} 
De acordo com Machado et al. (2000), entre diversos outros fatores, o custo da operação de transporte é dependente da distância, da existência de frete de retorno, das condições da rede viária, do nível de construção e manutenção de estradas, da eficiência das operações de carregamento e descarregamento, incluindo os tempos de espera, a quantidade de carga transportada, o pagamento de pedágios, combustível etc.

Atualmente, uma dificuldade enfrentada pelas empresas é o controle da carga e a correta distribuição do peso sobre os eixos dos veículos, devido aos diferentes tipos e volumes, espécies e comprimentos de madeira transportada. É ainda comum observar veículos de alta capacidade de carga trafegando pelas rodovias, pois proporcionam melhor desempenho operacional e custos reduzidos. Todavia, a segurança no trânsito e os riscos de acidentes com esses veículos passaram a ser uma preocupação constante por parte das empresas florestais, transportadores e do público em geral (SEIXAS, 2001).

Em razão do maior rigor quanto à fiscalização em cumprimento à legislação vigente, da necessidade de oferecer maior segurança no trânsito, maior conservação e redução dos custos de manutenção de estradas, a determinação do peso da carga na área florestal tornouse uma medida imprescindível para a otimização do transporte florestal rodoviário. Em outros países, já existem empresas utilizando balanças acopladas aos carregadores florestais, garantindo maior precisão na carga total transportada e melhor distribuição de peso por eixo do veículo. No Canadá, Michaelsen (1998) testou diversos modelos de balanças instaladas em composições rodoviárias, sendo que uma balança montada em grua de carregador florestal apresentou um erro em torno de $3 \%$ em relação à carga total.

No Brasil, o uso do Sistema de Pesagem no controle de cargas evitará que os veículos trafeguem acima ou abaixo do limite de peso estabelecido pela legislação, oferecendo maior segurança, maior vida útil aos veículos, maior conservação e redução nos custos de manutenção de estradas e, conseqüentemente, proporcionando a otimização do transporte florestal rodoviário.

O objetivo desta pesquisa foi realizar uma avaliação técnica de um Sistema de Pesagem no carregamento de madeira, visando mostrar a eficiência do equipamento com vistas à sua introdução nas empresas florestais.

\section{MATERIAL E MÉTODOS}

\section{1. Área de Estudo}

A pesquisa foi conduzida em áreas pertencentes à Rigesa Celulose, Papel e Embalagens Ltda., localizada no Município de Três Barras, Santa Catarina, entre os paralelos $26^{\circ} 07^{\prime} \mathrm{S}$ de latitude e $50^{\circ} 19^{\prime} \mathrm{W}$ de longitude e a $770 \mathrm{~m}$ de altitude. $\mathrm{O}$ tipo de solo predominante da região é o Latossolo Vermelho-Escuro, sendo o clima característico o Cfb (Köppen). A precipitação média anual é de aproximadamente $1.429,29 \mathrm{~mm}$, e a temperatura média anual situa-se em torno de $19,3^{\circ} \mathrm{C}$. O reflorestamento da empresa é constituído da espécie Pinus taeda, em regime de corte raso aos 17 anos.

Os dados foram coletados no carregamento de toras de pinus sobre veículos articulados (carreta) de tração 6 X 4, com capacidade líquida de $30.000 \mathrm{~kg}$. As toras possuíam comprimento médio de $2,40 \mathrm{~m}$ e diâmetro médio entre 18 e $25 \mathrm{~cm}$, sendo destinadas para o processo fabril, cuja distância média de transporte era de $15 \mathrm{~km}$.

\subsection{Descrição do Sistema de Colheita da Madeira}

O sistema de colheita utilizado na empresa era de “Árvores Inteiras", em que as operações de derrubada e empilhamento das árvores eram realizadas pelo feller direcional, constituído por uma máquina-base marca Caterpillar CAT 320 e cabeçote marca J. de Souza. Na sequiência, o arraste dos feixes de árvores até a beira da estrada era realizado por um skidder marca Caterpillar CAT 545. Na seqüência eram realizadas as operações de processamento das árvores, sortimento e classificação das toras, feito por um cabeçote harvester montado em uma máquina-base Caterpillar CAT 320.

\subsection{Descrição do Equipamento}

O carregador florestal analisado na pesquisa era composto por uma escavadeira de acionamento hidráulico com esteiras, marca Caterpillar CAT $312 \mathrm{~L}$, motor ATAAC Cat Diesel, potência nominal de $106 \mathrm{~kW}$, equipada com garra configuração Slasher com área útil de $0,60 \mathrm{~m}^{2}$ na primeira fase da pesquisa e com uma garra marca J. de Souza com área de $0,80 \mathrm{~m}^{2}$ e alcance médio de $7,5 \mathrm{~m}$, na segunda fase da pesquisa.

No conjunto foi montado o Sistema de Pesagem TB 300, que registrava e armazenava as leituras de pesos obtidos em cada ciclo do carregamento. O Sistema de Pesagem possuía um transdutor de pressão que 
media o aumento de pressão criada no sistema hidráulico fechado quando a carga era suspensa pela grua, sendo essa pressão diretamente proporcional ao peso da carga. O sinal de pressão hidráulica era convertido em sinal eletrônico, o qual era, então, transmitido ao computador de bordo instalado na cabine da máquina, acumulando as cargas individuais (Figura 1).

A Figura 2 ilustra o carregador florestal equipado com o Sistema de Pesagem TB 300; em detalhe a balança, o sensor e o computador de bordo.

\subsection{Procedimento de Pesagem}

Na primeira fase da pesquisa foi definido o ponto ideal de realização da pesagem, avaliando-se três procedimentos:

a) Pesagem no Ponto Baixo: registro do peso da carga no início do ciclo operacional, com a garra suspensa a $1 \mathrm{~m}$ do solo ou da pilha de toras, estabelecendose uma pausa de aproximadamente 5 seg para estabilização do equipamento.

b) Pesagem no Ponto Médio: registro do peso da carga durante o deslocamento da garra entre a pilha de madeira e a plataforma do veículo de transporte, sem a necessidade do estabelecimento de pausas.

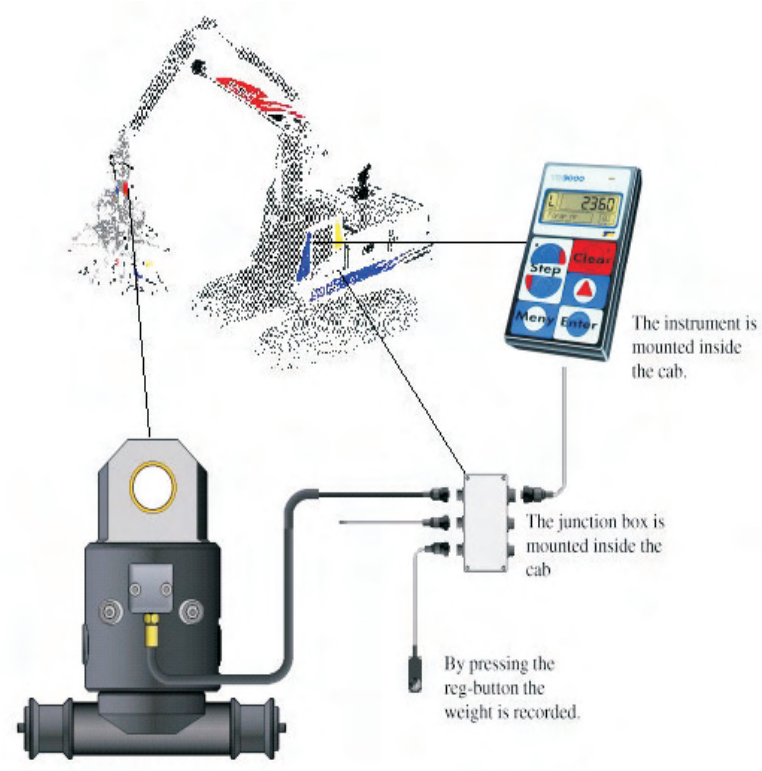

Figura 1 - Sistema de pesagem TB 300. Figure 1 - Weighing system TB 300. c) Pesagem no Ponto Alto: registro do peso da carga ao final do ciclo operacional, com a garra suspensa a $1 \mathrm{~m}$ acima da plataforma de carga do veículo de transporte, estabelecendo-se uma pausa de aproximadamente 5 seg para estabilização do equipamento.

A avaliação foi realizada com um operador de carregador florestal experiente na função e treinado na operação com o Sistema de Pesagem. Foram coletados dados de 30 veículos de transporte nos procedimentos baixo, médio e alto, determinando-se o tempo médio do ciclo operacional de carregamento por meio de estudo de tempos e movimentos. Simultaneamente, foi determinado o erro médio de pesagem, obtido pela diferença de peso entre o Sistema de Pesagem e a fábrica.

\subsection{Coleta de Dados}

Após definido o procedimento ideal de pesagem, realizou-se um estudo-piloto do ciclo operacional de carregamento florestal, com o intuito de definir o número mínimo de observações necessárias para proporcionar um erro de amostragem máximo de 5\%, em um nível
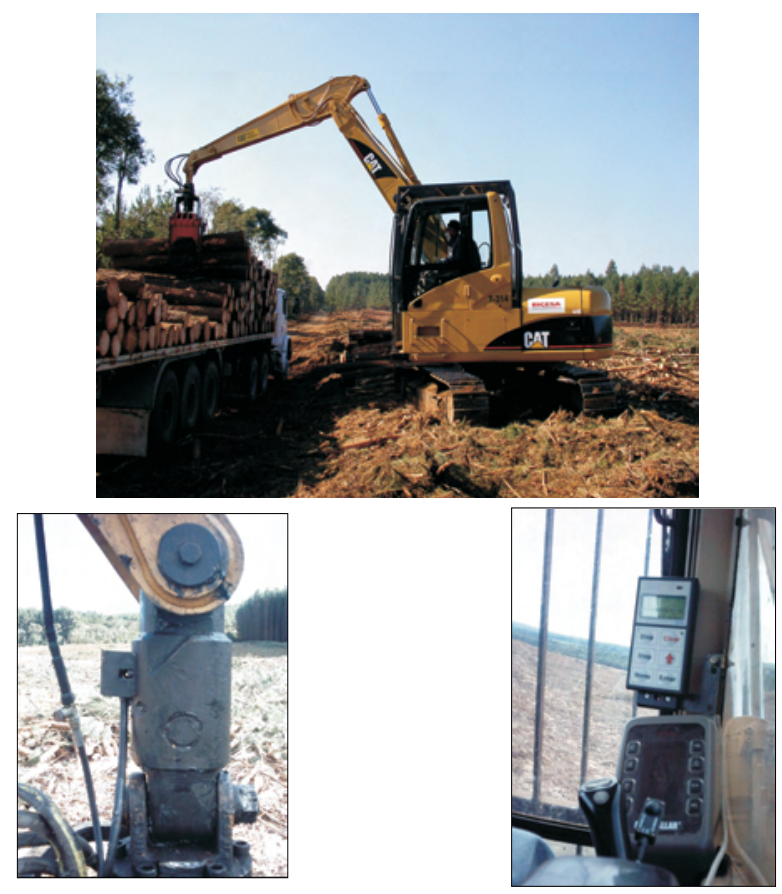

Figura 2 - Balança e computador de bordo do sistema de pesagem TB 300 montados no carregador florestal.

Figure 2-Scale and computer of the TB 300 weighing system offorest loader.

R. Árvore, Viçosa-MG, v.30, n.4, p.575-581, 2006 
de $95 \%$ de probabilidade, conforme metodologia proposta por Barnes (1968), através da seguinte equação:

$$
\mathrm{n} \geq \frac{\mathrm{t}^{2}+\mathrm{CV}^{2}}{\mathrm{E}^{2}}
$$

em que $\mathrm{n}=$ número mínimo de ciclos necessários; $\mathrm{t}=$ valor de t, Student, no nível de probabilidade desejado e (n-1) graus de liberdade; $\mathrm{CV}=$ coeficiente de variação, em porcentagem; e $\mathrm{E}=$ erro admissível, em porcentagem.

\subsection{Análise Técnica}

$\mathrm{Na}$ segunda fase da pesquisa, com a nova configuração da garra florestal foi realizada a análise do Sistema de Pesagem dentro do procedimento definido. Essa análise foi baseada nos seguintes parâmetros:

\section{a) Estudo de Tempos e Movimentos}

Foi realizado um estudo de tempos e movimentos por meio do método de tempo contínuo, conforme metodologia descrita por Barnes (1977). O ciclo operacional do carregamento foi dividido nas seguintes atividades parciais: AP - arrumação de pilha; DGC deslocamento da grua carregada e registro dos pesos; AC - arrumação da carga de toras no veículo de transporte; DGV - deslocamento da grua vazia; e DM - deslocamento da máquina. No estudo foram utilizados cronômetro centesimal, prancheta, formulários específicos e rádio receptor.

b) Eficiência do Sistema de Pesagem

A eficiência do Sistema de Pesagem foi determinada por meio do registro dos pesos individuais em cada ciclo operacional e dos pesos totais no carregamento de 114 veículos de transporte. Os pesos registrados foram, então, comparados com os pesos reais obtidos na balança da fábrica.

A exatidão do equipamento foi verificada pelo cálculo das diferenças porcentuais entre as leituras de peso obtidas com o Sistema de Pesagem e a balança da fábrica. A precisão foi verificada pelo cálculo da média dos desvios porcentuais. Além disso, verificou-se, pela aplicação do teste " $t$ " para dados pareados, se os registros de pesos obtidos pelo Sistema de Pesagem diferiam estatisticamente, a $95 \%$ de probabilidade, dos valores de pesos reais conseguidos na balança da fábrica.

\section{RESULTADOS E DISCUSSÃO}

\subsection{Ponto Ideal de Pesagem}

Analisando os resultados do Quadro 1, verificouse que, apesar de não apresentar diferença significativa em relação ao tempo total de carregamento e ao erro médio de pesagem, o procedimento de pesagem baixo apresentou os melhores resultados, sendo adotado como procedimento-padrão de pesagem. Além disso, os resultados comprovaram a recomendação do fabricante em relação à adoção desse procedimento. Tal fato pode ser explicado no momento da carga, quando é criada uma pressão interna no cilindro, a qual diminui com o tempo, proporcionando, portanto, maior erro na leitura. Assim, verificou-se a importância da realização da pesagem no início de cada ciclo operacional com a garra suspensa.

Quadro 1 - Tempo médio do ciclo operacional do carregamento florestal e diferença de peso obtidos nos três procedimentos estudados

Table 1 - Mean time of forest load operational cycle and weight difference in the three studied procedures

\begin{tabular}{|c|c|c|c|c|}
\hline \multirow[t]{2}{*}{$\begin{array}{l}\text { Procedimento de } \\
\text { Pesagem }\end{array}$} & \multirow{2}{*}{$\begin{array}{c}\text { Tempo Médio } \\
\text { do Ciclo Operacional } \\
(\min )\end{array}$} & \multicolumn{2}{|c|}{$\begin{array}{c}\text { Diferença de Peso } \\
(\mathrm{kg})\left({ }^{1}\right)\end{array}$} & \multirow[t]{2}{*}{$\begin{array}{l}\text { Erro Médio } \\
\qquad(\%)\left({ }^{2}\right)\end{array}$} \\
\hline & & Média & Desvio & \\
\hline Baixo & $20,4 \mathrm{a}$ & 357,1 & 167,7 & 1,06 a \\
\hline Médio & $21,7 \mathrm{a}$ & 563,0 & 417,0 & 1,83 a \\
\hline Alto & 20,1 a & 448,0 & 304,5 & 1,45 a \\
\hline Testemunha & 19,3 a & - & - & - \\
\hline
\end{tabular}

(a) As médias seguidas por mesma letra não diferem entre si.

( $\left.{ }^{1}\right)$ Diferença média de peso e desvio padrão entre a balança da fábrica e o sistema de pesagem TB 300.

$\left({ }^{2}\right)$ Erro médio de pesagem entre a balança da fábrica e o sistema de pesagem TB 300. 


\subsection{Análise Técnica}

a) Estudo de Tempos e Movimentos

O Quadro 2 ilustra os tempos médios dos elementos do ciclo operacional do carregamento florestal com e sem o Sistema de Pesagem TB 300. Como pode ser visto nesse quadro, o uso do Sistema de Pesagem acarretou aumento no tempo de carregamento na ordem de $19 \%$, devido à introdução das pausas para estabilização do equipamento.

A composição porcentual dos tempos do ciclo operacional do carregador florestal sem e com o Sistema de Pesagem são apresentados nas Figuras 2 e 3, respectivamente. Como pode ser observado, os elementos deslocamento da grua carregada, deslocamento da grua vazia e arrumação de carga corresponderam, juntos, a mais de $90 \%$ do tempo total do ciclo operacional em ambas as situações analisadas. Os elevados tempos de arrumação de carga foram influenciados pela qualidade das pilhas de madeira na beira da estrada.

O elemento deslocamento da grua carregado no ciclo operacional do carregamento com o Sistema de Pesagem apresentou um tempo superior em relação ao ciclo sem o Sistema de Pesagem, com 49,6\% e 36,5\%, respectivamente. Essa diferença deveu-se à necessidade do estabelecimento de pausas para estabilização da balança e posterior registro das leituras. No entanto, houve redução significativa no tempo de arrumação de carga de $31,5 \%$ para $22,6 \%$. Tal fato se deveu ao maior cuidado do operador na realização do carregamento com o Sistema de Pesagem, que poderá proporcionar uma redução dos custos operacionais devido ao aumento da disponibilidade mecânica e à vida útil do conjunto.

O tempo total médio do carregamento foi de 13,6 min para a testemunha e de 16,8 min para o Sistema de Pesagem. É importante destacar que a nova configuração de garra florestal em substituição à garra slasher possibilitou ganhos significativos de produtividade em relação à primeira fase da pesquisa.

Quadro 2-Tempo médio do ciclo operacional do carregamento florestal com e sem o sistema de pesagem TB 300

Table 2 - Mean time of forest load operational cycle with and without the TB 300 weighing system

\begin{tabular}{lcccccc}
\hline $\begin{array}{l}\text { Situação de } \\
\text { Pesagem }\end{array}$ & \multicolumn{4}{c}{$\begin{array}{l}\text { Tempo Médio de } \\
\text { Carregamento (min) }\end{array}$} & $\begin{array}{c}\text { Tempo } \\
\text { (min) }\end{array}$ \\
\cline { 2 - 5 } & AP & DGC & AC & DGV & DM & Total \\
\hline TB 300 & 1,0 & 8,3 & 3,8 & 3,4 & 0,3 & 16,8 \\
Testemunha & 0,9 & 5,0 & 4,3 & 3,2 & 0,3 & 13,6 \\
\hline
\end{tabular}

Testemunha

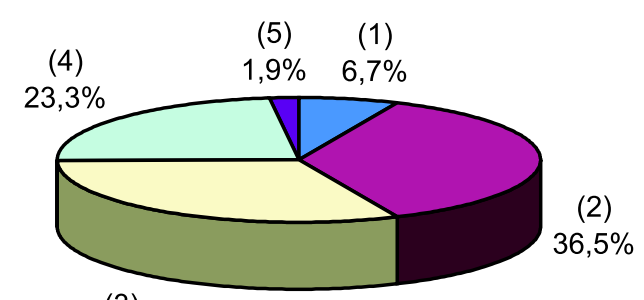

(3)

\section{$31,5 \%$}

Sistema de Pesagem

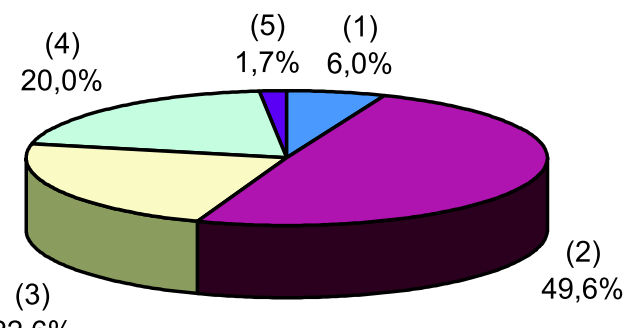

$22,6 \%$

(1) Arrumação de pilha, (2) Deslocamento da grua carregado, (3) Arrumação de carga, (4) Deslocamento da grua vazio e (5) Deslocamento da máquina

Figura 3 - Composição porcentual do tempo total do ciclo operacional do carregador florestal sem e com o sistema de pesagem.

Figure 3 - Total time percent composition of the forest load operational cycle with and without the weighing system.

b) Eficiência do Sistema de Pesagem

O Quadro 3 ilustra as diferenças médias de pesos obtidas entre o Sistema de Pesagem TB 300 e a balança da fábrica (real). Como pode ser visto, a diferença média foi de $217,9 \mathrm{~kg}$ em relação a uma carga total de 30.000 $\mathrm{kg}$, a qual era a capacidade dos veículos de transporte. Esses resultados proporcionaram um erro médio de $0,72 \%$ em termos absolutos, quando o máximo permitido pela legislação é de 5,0\%, mostrando, portanto, a funcionalidade e eficiência do Sistema de Pesagem na operação de carregamento florestal.

Pela aplicação do teste "t" para dados pareados, verificou-se que não existiu diferença significativa, a $95 \%$ de probabilidade, entre as leituras de peso obtidas pelo Sistema de Pesagem e as conseguidas na balança da fábrica (Quadro 3).

R. Árvore, Viçosa-MG, v.30, n.4, p.575-581, 2006 
Quadro 3 - Diferenças médias de pesos entre o sistema de pesagem e a balança da fábrica

Table 3 - Mean weight differences between the weighing system and the industry weighing

\begin{tabular}{|c|c|c|c|c|}
\hline \multirow{2}{*}{$\begin{array}{c}\text { Carga } \\
\left(\mathrm{n}^{\circ}\right)\end{array}$} & \multicolumn{3}{|c|}{ Pesos $(\mathrm{kg})$} & \multirow{2}{*}{$\begin{array}{c}\text { Erro Médio } \\
(\%)\end{array}$} \\
\hline & ТВ 300 & Fábrica & Diferença & \\
\hline 1 & 29.026 & 29.210 & 184,0 & 0,63 \\
\hline 2 & 30.665 & 30.930 & 265,0 & 0,86 \\
\hline 3 & 30.951 & 31.290 & 339,0 & 1,08 \\
\hline 4 & 31.438 & 31.830 & 392,0 & 1,23 \\
\hline 5 & 31.074 & 31.370 & 296,0 & 0,94 \\
\hline 6 & 29.655 & 29.910 & 255,0 & 0,85 \\
\hline 7 & 30.457 & 30.830 & 373,0 & 1,21 \\
\hline 8 & 30.748 & 31.140 & 392,0 & 1,26 \\
\hline 9 & 30.379 & 30.780 & 401,0 & 1,30 \\
\hline 10 & 29.765 & 30.170 & 405,0 & 1,34 \\
\hline . & . & . & . & . \\
\hline . & . & . & . & . \\
\hline . & . & . & . & . \\
\hline 104 & 31574 & 31740 & 166 & 0,52 \\
\hline 105 & 30.473 & 30.330 & 143,0 & 0,47 \\
\hline 106 & 30.686 & 30.680 & 6,0 & 0,02 \\
\hline 107 & 29.673 & 29.500 & 173,0 & 0,59 \\
\hline 108 & 31.578 & 31.440 & 138,0 & 0,44 \\
\hline 109 & 29.803 & 29.690 & 113,0 & 0,38 \\
\hline 110 & 30.901 & 30.870 & 31,0 & 0,10 \\
\hline 111 & 31.865 & 31.700 & 165,0 & 0,52 \\
\hline 112 & 29.815 & 29.710 & 105,0 & 0,35 \\
\hline 113 & 31.567 & 31.560 & 7,0 & 0,02 \\
\hline 114 & 30.993 & 30.930 & 63,0 & 0,20 \\
\hline Média & $30.149,3$ & $30.273,4$ & 217,9 & 0,72 \\
\hline Desvio & $2.052,2$ & $2.093,3$ & 135,6 & 0,440 \\
\hline $\mathrm{n}$ & & & & 114 \\
\hline " $t$ " calcul & & & & $-5,89$ (n.s.) \\
\hline "t" $(5 \%, 1$ & g1) & & & 1,98 \\
\hline
\end{tabular}

(n.s.) - não significativo a $95 \%$ de probabilidade.

Na Figura 4, mostra-se que os pesos obtidos em todos os veículos estavam dentro da tolerância de 5\% estabelecido pela legislação de trânsito.

\subsection{Produtividade}

A produtividade média do carregador florestal equipado com o Sistema de Pesagem, em toneladas por hora efetiva, foi de 108,4 toneladas, enquanto sem o Sistema de Pesagem foi de 133,9 toneladas. A redução de $19 \%$ na produtividade foi devida às pausas necessárias para a estabilização da balança e o registro das leituras, proporcionando, em média, redução de uma carga (veículo) por hora. Todavia, essa perda de produtividade poderá ser recuperada com o aumento da disponibilidade mecânica do conjunto, explicado pela redução da necessidade de "bateção" de cargas.

O Sistema de Pesagem poderá, ainda, proporcionar vários benefícios para a otimização do transporte florestal rodoviário, como melhoria na qualidade do carregamento, maior vida útil do carregador florestal e veículos de transporte, maior segurança no trânsito, maior conservação das estradas e redução nos custos de manutenção das estradas.

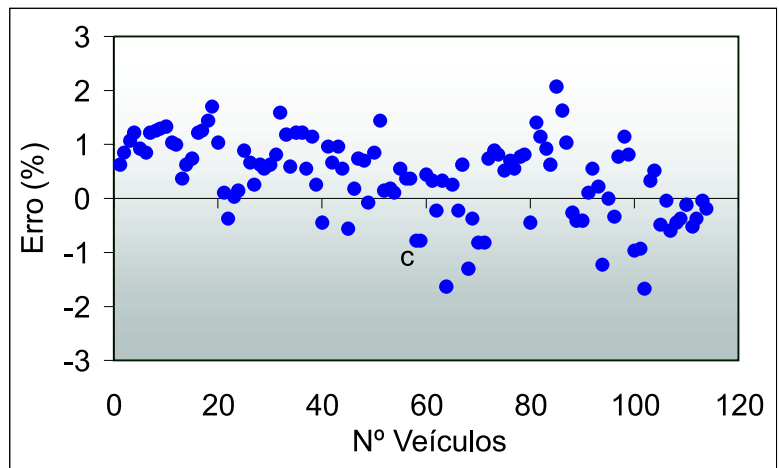

Figura 4 - Distribuição porcentual do erro do sistema de pesagem.

Figure 4-Percent error distribution of the weighing system.

\section{CONCLUSÃO}

Com base nos resultados desta pesquisa, as seguintes conclusões podem ser apresentadas:

a) O procedimento de pesagem "Baixo" apresentou os melhores resultados, sendo adotado e recomendado como procedimento-padrão.

b) Com a nova configuração da garra florestal utilizada na segunda fase da pesquisa, o tempo médio de carregamento foi reduzido significativamente, apesar da redução de $19 \%$ na produtividade com o uso do Sistema de Pesagem.

c) Apesar da redução de produtividade, o Sistema de Pesagem proporcionará maior disponibilidade mecânica do carregador florestal, mantendo a sua eficiência operacional.

d) O Sistema de Pesagem mostrou-se eficiente na determinação do peso da carga, em que se obteve um erro médio de $217,9 \mathrm{~kg}$, representando uma variação média de $0,72 \%$, quando o máximo permitido pela legislação é de $5 \%$. 


\section{REFERÊNCIAS BIBLIOGRÁFICAS}

BARNES, R.M. Estudos de movimentos e de tempos - projeto e medida do trabalho. 6 . ed. São Paulo: Edgard Blucher, 1977.635 p.

BARNES, R.M. Motion and time study: design and measurement ok work. 6 ed. New York: John Willey \& Sons, 1968. 799 p

MACHADO, C. C.; LOPES, E. S., BIRRO, M. H. Elementos básicos do transporte

florestal rodoviário. Viçosa, MG:

Universidade Federal de Viçosa, 2000. 167 p.
MiCHAELSEN, J. A. A comparative evaluation of onboard weight scales. Québec, Canadá. 1998.6 p.(FERIC Technical Note. TN-275).

SEIXAS, F. Novas tecnologias no transporte rodoviário de madeira. In: SIMPÓSIO BRASILEIRO SOBRE COLHEITA E TRANSPORTE FLORESTAL, 5., 2001, Porto Seguro. Anais... Porto Seguro: UFV/SIF, 2001. p. 1-27. 